Jaspal, R., Carriere, K. \& Moghaddam, F. (2016). Bridging micro, meso and macro processes in social psychology. In J. Valsiner, G. Marsico, N. Chaudhary, T. Sato \& V. Dazzani

(eds.), Psychology as a science of human being: The Yokohama Manifesto. New York: Springer.

\title{
Bridging Micro, Meso and Macro Processes in Social Psychology
}

\author{
Rusi Jaspal \\ De Montfort University, Leicester, UK \\ Kevin R. Carriere and Fathali M. Moghaddam \\ Georgetown University, Washington, USA
}

Social psychology and cultural psychology have long been concerned with exploring the relationship between individuals and society (Valsiner \& Rosa, 2007). A broad division has evolved toward the study of this relationship, with North American researchers focusing more on individual-level processes and European social psychology giving relatively more attention to collective processes. A few researchers have attempted integration, on the assumption that the successful elaboration of the individual's relationship with the social world requires an analysis that acknowledges the multiple levels of analysis (Doise, 1980; Valsiner \& Rosa, 2007). At least three levels of analysis should be acknowledged in research on social behavior:

- the micro level constitutes the smallest unit of analysis, typically the individual. This may include inter alia personality traits, cognitive styles, attributional tendencies and individual attitudes;

- the meso level focuses on the various social group memberships of the individual, such as their family, neighborhood, ethnicity, nationality etc;

- the macro level may be considered the highest level of analysis and would include societal ideologies and social representations, such as the Indian caste system which organizes caste groups within a hierarchical system, or the state ideologies of assimilation versus multiculturalism.

More integration is needed to merge 'psychological' researchers exploring social behavior, focused on the micro level and individualistic theories which view the individual as the primary 
unit of analysis (see Powell, 2007), with 'sociological' researchers focused on the meso and macro levels of analysis and viewing societal structure as a key starting-point (see Rohall, Milkie \& Lucas, 2011). The lack of integration of these levels of analysis has resulted in partial explanations of complex social psychological phenomena (Jaspal, 2014; Harré \& Moghaddam, 2012; Moghaddam, 2002). Thus, the puzzle of individual-society integration remains, despite all the progress we have made in developing theories in psychology, despite what seem to be countless empirical studies using traditional and non-traditional methods, and despite growth in a vast range of non-mainstream psychologies, including cultural psychology, critical psychology, and narrative psychology. The puzzle remains, despite the apparent influence of Lev Vygotsky, Jerome Bruner, Rom Harré, and despite the growing visibility of progressive journals such as Culture \& Psychology and Feminism \& Psychology. Despite all this, micro-level approaches to psychological phenomena remain the dominant paradigm and there has been little attempt to synthesize the three prime levels of analysis. In this chapter, we explore the inter-dependent relations between behavior at macro, meso, and micro levels.

To better understand the puzzle, consider the example of human rights and duties. We know from the research of Willem Doise and his group in Geneva that the ideas integral to the United Nations Declaration of Human Rights are now shared by young people in many different countries around the world (Doise, Spini \& Clemence, 1999; Doise, Staerkle, Clemence \& Savory, 1998). Through what mechanisms are these ideas spread? Why do we observe differences in attitudes among specific groups and societies? In our ongoing research at Georgetown, we are finding that there are differences between the attitudes of men and women on human rights and duties: women tend to be more supportive of rights associated with health, education, and social welfare in general. In attempting to explain these gender differences, one might point to 'socialization processes', but this is too vague. In our view, differences in attitudes and perspectives arise from the complex interaction between the micro, meso and macro levels of analysis. Social constructions of reality are processed by the individual in accordance with both their individual identities consisting of personality traits, attitudes and knowledge structures and their group memberships and the ideologies and knowledge structures associated with them. Answering these questions necessitates an integration of the various levels of analysis.

Critics have repeatedly pointed out that traditional psychology is reductionist and focuses too much on the self-contained individual. Traditional studies examine intra-personal processes 
in a vacuum. Studies on group processes, focusing on 'conformity', 'groupthink' and other such meso-level phenomena, have identified ways in which individuals and groups are meshed together. Studies on stereotype threat, values, and attributional style have examined how aspects of culture can influence individual level thinking. But the puzzle remains: What in practice are the means by which the macro level processes become linked to meso and micro level processes? Pointing to 'culture' is not enough. We need theoretical ideas that point to more concrete links, and more practical mechanisms of influence. One proposal has been a theoretical synthesis of Identity Process Theory and Social Representations Theory as a means of integrating the three prime levels of analysis and of providing an analysis that is social psychological in essence.

\section{Social Representation, Identity and Action}

A central proposition in this chapter is that a social psychological framework that can integrate the micro, meso and macro levels of analysis is necessary (see Jaspal, Nerlich \& Cinnirella, 2014). In exploring the micro level, it seems that individuals strive to maintain and protect their identity, that is, their understanding of the kind of person they are and what makes their groups the kinds of groups they are, in the face of challenges to it - incidentally, these challenges often originate at the meso and macro levels. For instance, new legislation that is perceived as discriminating against one's group in society or a state-level revolution that forces one to rethink one's position in the state can both challenge identity at the micro level. In attempting to articulate the inter-relations between the micro, meso and macro levels, two theories from social psychology - Identity Process Theory and Social Representations Theory - have proven to be particularly useful.

Identity Process Theory (Breakwell, 1986; Jaspal \& Breakwell, 2014) sheds light on how people construct, regulate and protect their identities. The theory proposes that people construct their sense of identity through engagement with two psychological processes, namely (i) assimilation-accommodation and (ii) evaluation.

- The assimilation-accommodation process refers to the absorption of new information in the identity structure and to the adjustment that takes places for it to become part of the structure. For instance, when the Islamic Revolution took place in Iran in 1979, many Iranians simply did not think of themselves as religious beings - some only nominally self-identified as Muslim but did not view this as a particularly meaningful aspect of 
identity. After the Revolution, Islam was rendered a salient identity element and a primary means of self-definition and was, thus, assimilated to identity. Yet, in order for this to become a part of identity (accommodation), room had to be made for it in the identity structure - some people begin to question the other activities and practices that they engaged in, which were now defined as "un-Islamic" by the Iranian authorities.

- The evaluation process confers meaning and value upon the contents of identity. For instance, with the emergence of the self-category African American, which has gradually replaced the category Black, Americans of African descent are able to think about their identity in terms of cultural heritage, rather than race (Philogène, 1999). This enables individuals to construct an identity that can overcome the historical legacy of racism and, thus, focus on positivity rather than negativity.

These processes function to create specific desirable end-states for identity, which are referred to as "identity principles." Identity processes are guided by the following principles:

- continuity - a continuous temporal thread connecting past, present and future

- distinctiveness - uniqueness and differentiation from others

- self-efficacy - competence and control

- self-esteem - personal and social worth

The theory suggests that when identity processes cannot, for whatever reason, comply with psychologically salient principles, identity is threatened and the individual will engage in strategies to cope with the threat. A coping strategy is defined as "any activity, in thought or deed, which has as its goal the removal or modification of a threat to identity" (Breakwell 1986, p. 78). Coping functions at three levels:

- Intrapsychic strategies include inter alia denial and re-conceptualization.

- Interpersonal strategies are those that rely on altering one's existing relationships with other people in order to minimize the threat, such as self-isolation.

- Intergroup strategies make use of intergroup dynamics in order to safeguard identity and include making strategic use of multiple group memberships and actively seeking group support through social networks or consciousness raising/ self-help groups.

A central proposition of the theory is that people do not construct their identities in a social vacuum but rather through engagement with social norms, values, ideologies etc. These can be collectively referred to as social representations. Moscovici's (1998) Social Representations 
Theory explains the development and dissemination of social knowledge. Social representations are defined as systems of values, ideas and practices regarding a given social object. They are context-specific and create what one might call a shared social reality in which thinking and discussion regarding issues like politics, science, and technology can take place. Moreover, social representations are tools for communicating with one another - we understand each other, not just through language itself, but also through the social representations that underpin the words and phrases that we utter. Moscovici (1988) outlines two processes that give rise to social representations, namely (i) anchoring and (ii) objectification. Anchoring refers to the process of making something unfamiliar understandable by linking it to something familiar. For instance, when the first AIDS cases emerged in gay communities of New York and San Francisco, the virus was often linked to the plague (e.g. "gay plague"). Objectification is the process whereby unfamiliar and abstract objects are transformed into concrete and "objective" common-sense realities. For instance, the metaphors of "freedom fighter" versus "terrorist" demonstrate the radically different social, political and ethical perspectives that Israelis and Palestinians often take in relation to their long-standing intergroup conflict (Jaspal \& Coyle, 2014).

In modeling the individual's relationship with a social representation, which is an important way of reconciling the micro, meso and macro levels, Breakwell (2014) points to the following factors:

- Awareness - people differ in their level of awareness of a social representation. For example, many people living in the West are exposed only to negative social representations of Israel/Palestine, which are anchored in conflict and violence, and may be unaware of more positive social representations of Israeli contributions to science and of Palestinian contributions to culture, for instance.

- Understanding - people vary in the extent to which they understand a social representation. For instance, although many Iranians are aware of the social representation that Israel is an illegitimate state, they may not all understand the historical and political underpinnings of this representation.

- Acceptance - individuals accept a social representation to varying degrees. Although political institutions may attempt to encourage positive social representations of Islam in the face of growing Islamophobic prejudice, some individuals may simply refuse to accept these representations and perpetuate the view that Muslims are "Other". 
- Assimilation - once accepted, the social representation needs to be assimilated to the network of existing social representations held by the individual. An American who votes for the Republican Party may accept the social representation of anthropogenic climate change but this will then need to be reconciled with other potential social representations, e.g. that the theory of anthropogenic climate change is a scam designed to undermine the US economy.

- Salience - individuals' awareness and understanding of a social representation will likely depend on the extent to which the representation is salient in any given context. The media, for example, plays a pivotal role in rendering salient social representations and have, therefore, been described as performing an agenda-setting function.

Breakwell's $(2001,2014)$ formal alignment of Identity Process Theory with Social Representations has opened up further opportunities for integrating the micro, meso and macro levels of analysis. Identity Process Theory acknowledges the importance of social representations in determining identity content (i.e. the information that is accepted and assimilated), and the impact that social representations can have for identity processes (i.e. whether they are threatened or enhanced). For example, a social representation that challenges one's self-esteem, continuity and so on is unlikely to be accepted, simply because human beings are motivated to protect their identities. It is argued that this integrative framework of representation, identity and action can be useful in understanding how the micro, meso and macro levels relate to one another in psychology.

\section{Symbols and Identity: The Islamic Veil and the Confederate Flag}

In 1979, Ayatollah Khomeini led the Islamic Revolution in Iran, which led to the departure of the Shah and his family from Iran and to the establishment of the Islamic Republic of Iran. Prior to the Revolution, Iran had been seeking rapprochement with the West and had close alliances with both the US and Israel. While officially a Shia Muslim country, the Iranian monarchs presented themselves as more European than Middle Eastern and this was mirrored in the abundance of cinemas showing Western films, French cafes, bars, clubs and so on. After the Revolution, this all changed. The US and Israel, once Iran's allies, were positioned as the Big Satan and Little Satan, respectively, and the Islamic identity was to be rekindled and restored in Iran. The powerful leadership and charismatic rhetoric of Ayatollah Khomeini, the new Supreme Leader of 
the Islamic Republic, paved the way towards a complete transformation of the social, political and ideological landscape of Iran. Post-revolution Iran itself provided an exciting natural laboratory for the examination of social psychological phenomena. It clearly reflected the interrelations between macro-level ideologies (anti-Americanism, anti-West, Islamicization) and the meso-level, that, is how groups and identities in Iran were aligned with these ideologies. The underpinning mechanism was the construction of social representations reflecting these ideologies and their dissemination to the public - they were rendered salient and Iranians were expected to accept and assimilate them to their identities.

What was particularly fascinating about the post-Revolution era was what Islamic fundamentalists in Iran had to say about hejab, the Islamic veil. The third author of this chapter travelled around his native Iran, asking people "Why do you give so much importance to a piece of cloth? Was the great revolution for a piece of cloth? Does the focus on this piece of cloth not trivialize the revolution?" These questions sought to explore the meaning and significance of the hejab both to the Islamic Revolution and to Iranians themselves. At this point, Islamic fundamentalists were using every means possible, from verbal persuasion to lethal violence, from social pressure to throwing acid in the face of 'immorally dressed' females, to force Iranian women to wear the veil. The hejab had come to constitute a social representation, that is, a tangible objectification of the Islamic Revolution and the ideals for which it stood. For the Islamic revolutionaries, it epitomized inter alia modesty, morality and Islam, and it represented much more than a piece of cloth but a means of distinguishing post-Revolution Iran from the "immoral" Iran of the Shah. In this context, we can see how the macro-level state ideologies of Islamicization and assimilation were objectified in terms of the hejab and then used, at the mesolevel, to delineate those faithful to the ideals of the Revolution versus the "heretics". The power of this symbol is further demonstrated by the ways in which the Islamic veil has continued to create such scandal in French public schools. Indeed, "[b]y late 1989, many Islam as a new threat and Muslim students as its carriers" (Bowen, 2007, p. 66). The veil, as a social representation of Islam, came to transform individuals into members of this threatening outgroup, blurring the boundaries between micro and meso.

In Iran, the requirement that all women wear this symbol of the Islamic Revolution ensures the salience of this social representation and serves to encourage its acceptance among the Iranian population. Even the way in which the hejab is worn by women is often used as a 
marker of their political identity - Iranian women who wear it loosely with much of their hair visible are often viewed as attempting to evade the legal requirement of wearing the hejab without actually contravening it and they may in fact be chastised by police officers for the misdemeanor of "bad hejab", while those women who wear it more tightly with none of their hair visible may be viewed as buying into the ideals of the Islamic Revolution. This use of the hejab itself reflects particular group identities.

In thinking about how Iranian themselves respond to this social representation of the state, identity processes are important. Those Iranians who participated in the Revolution with hopes for greater social and political freedoms would plausibly experience threats to their sense of continuity when they were faced with the imposition of the hejab, while those who perceived the Shah's modernization processes as "alien" to Iranian culture may have experienced a boost to their sense of continuity since the "threat" of Westernization had passed and the hejab symbolized to return to their "origins". Thus, the constant salience of the hejab was experienced as a threat to identity among some and as an enhancement of identity among others, and how it was experienced depended, and continues to depend, upon group identities and political loyalties.

How individuals responded behaviorally is also significant. As discussed above, some Iranian women attempt to challenge authority by wearing the hejab unconventionally, which may be conceptualized as an act of negativism, that is, "the state of mind which one is in when one feels a desire or a compulsion to act against the requirements or pressures from some external source. This may mean refusing to do what others wish or even doing the opposite of what is required or expected in a given situation" (Apter, 1983, p. 79). This interpersonal strategy for coping with threats imposed at the macro level can provide, at meso and micro levels, the perception that one is self-efficacious and has agency over one's identity, life and future. Conversely, others embrace the hejab as an important aspect of their identities as Iranian women and proudly wear it to symbolize their entwined national and religious identity, as per the ideology of the Islamic Revolution. In short, the hejab constitutes a social representation in Iran - it is embraced by some and rejected by others. The meanings that this representation activates for people are entwined with their individual and social identities, as well as their histories and political affiliations.

The Islamic veil is not the only piece of cloth that can acquire meaning and significance 
for millions of people. Another example is the perception held by many US Southerners toward the Confederate Flag. It is seen by some as representing a proud, valiant, and gracious South, and by others as symbolizing a South still mired in racism, bigotry, and backwardness (Coski, 2005). Like the Islamic veil in Iran, the Confederate Flag had come to be fiercely defended by many people in the South. For some, it represents the distinctiveness of Southern identity and constitutes a source of regional self-esteem. It evokes particular social memories (Lyons, 1996), which serve to bolster identity among some Southerners. Like the Islamic veil in Iran, the Confederate Flag can provide a sense of continuity over time, keeping in tact an identity that is grounded in the history of the South - it connects past, present and future. The sense of continuity is of course further maintained through the establishment and maintenance of monuments commemorating those who served on the Confederate side in the American Civil War. For many Southerners, the Confederate Flag poses a threat to identity because it is a social representation that evokes low self-esteem on the basis of Confederate principles which may be perceived as racist and as glorifying the practice of slavery. Conversely, for others, it may actually promote pride and, thus, self-esteem on the basis of the ingroup's history. Although the Islamic fundamentalists defending the Islamic veil and the Southerners defending the Confederate Flag would see one another as being very different, they do in fact converge in one key respect: they both adopted a piece of cloth as a cultural carrier. The respective pieces of cloth have come to constitute a social representation which evokes ideas, images and affect in people's minds.

Cultural carriers are the means by which the values, attitudes, and the normative system of a society are propagated and passed on to the next generation. Social representations like physical entities, such as flags and standards, ensure that these values, attitudes and norms are safeguarded and communicated across generations. At a basic level, these representations facilitate collective remembering since they anchor the present to the past by fixating on a specific, symbolic aspect of our group's history. The Confederate Flag evokes the Southern identity in opposition to the Northern identity. Consider the following example from the novel War and Peace:

"This is my hour!" thought Prince Andrei, seizing the staff of the standard and exulting as he heard the whistle of bullets unmistakenly aimed at him. Several soldiers fell.

"Hurrah!" shouted Prince Andrei, and scarcely able to hold up the heavy standard he 
ran forward in the unhesitating conviction that the whole battalion would follow him.

And it was indeed only for a few steps that he ran alone. One soldier started after him, then another, until the whole battalion with a shout of 'Hurrah' had dashed forward and overtaken him.

Tolstoy, L. (1869/1957, vol 1, p. 325).

The hero rallying soldiers around a military standard during a battle, schoolchildren saluting the national flag in front of their school, sports fans cheering the team mascot are all familiar scenes, involving well-known story lines. When Tolstoy describes in War and Peace how Prince Andrei turned the tide of battle by picking up the regimental standard, running with it at the enemy, and inspiring other Russian soldiers to turn around and fight the French invaders, we immediately recognize what is happening. When Prince Andrei is wounded and falls with the flagstaff in his hand, losing blood and moaning 'like a child', and when Napoleon passes by and says of the Prince “That's a fine death!” (Tolstoy, 1869/1957, vol.1, p. 338), this is a story line we know well. The regimental standard carries us along with it, inspiring images of heroism, glory, love for country, and sacrifice. It is easy to see how the group's self-esteem may be embodied by the standard.

Uniforms, medals, regimental standards, national flags, the military salute, the sound of the military bugle - these are all cultural carriers that we understand and are influenced by. They facilitate feelings of continuity, self-efficacy, self-esteem and distinctiveness, and provide a sense of "us" versus "them" (Lyons, 1996). They ensure that group identities, and the ideologies that underpin them, remain salient, and that the positive images associated with these identities are accepted and internalized by every group member. These are concrete mechanisms through which macro societal processes become wedded to meso group level processes and micro individual level processes.

\section{Human Rights and Duties}

The domain of human rights and duties is a similarly fruitful arena in which to explore the interconnections between the micro, meso and macro levels of societal functioning. The National Archives houses many important symbols of human rights and duties. In this building, many thousands of documents and articles are stored and thousands of others are on display - Michael 
Jackson's white gloves, Michelle Obama's dress when Barack Obama won the 2008 election, and many historical documents. Each of these items and many others in the National Archives is a personal item belonging to an individual which has acquired greater social significance - it represents their owners and, perhaps more importantly, what their owners themselves stood for. More generally, each document is placed within the Archives because it is seen as of historic importance. However, 'historic importance' can be interpreted in many different ways. Imagine, instead, a different kind of display: a room filled with the listings of the latest Yellow Pages, or of the list of decisions made by a local school teacher. While possible, such a room was not on display.

Instead, there are exhibits of famous individuals throughout history - photos of the first astronauts, the first television appearance of a President, and letters sent from Presidents to friends, loved ones, and dignitaries. There is not a room with photos of the 'average Joe' from the office, or 'average citizen' who reads the current trends in science. Instead, we are faced with rooms filled with meticulously selected objects, intending to evoke certain experiences within the viewers. The objects link the individual viewers with the collectively known personalities and events. They function as social representations as they evoke social memories among visitors. These items construct a sense of continuity, sustaining aspects of the ingroup's history and reminding citizens of the highs and lows of the journey to where we are now. They render salient those aspects of our history that can provide a sense of pride and self-esteem, ensuring that self-identification with the group and its ethos continue. Crucially, each visitor is targeted individually, clearly demonstrating the synthesis of the micro and macro levels. Groups also strive to construct their past, present and future as being characterized by unity, rather than division, and differences between the ingroup and outgroups are often accentuated. This maintains the group's distinctiveness (through internal cohesion) and, thus, its integrity.

The main attraction in the National Archive is presented in a very special way. After a long line, behind an ornate gate, with a security guard controlling the number of people who pass the gate, you can walk around this large rotunda and view the original copies of the Bill of Rights and the United States Constitution. The extravagance, the security, the reverence placed on these two historic pieces of paper creates a feeling of importance and sacredness. It also elevates the pieces of paper to symbolic status, demonstrating their centrality to the state and the ideology underlying it. Here, the foundation of a country, built on rights for all (free) men, is protected, 
watched over, and revered. The unique treatment of these documents, the restrictions and limitations on their viewing and holding, gives them special importance. Here, through their distance, they become even more impressive. It is therefore a social representation of the nation.

The display of the Bill of Rights shows how cultural carriers are exhibited in such a way as to transfer the values of rights and duties to the next generation. Here, we have various levels of distancing - the large empty room, the bulletproof glass, the limitation of the number of viewers at any one time. The security guards are present to protect these documents and what they stand for. The Archives is a display of duty - to honor and remember the past, to instill the ideas of the rights written down from long ago. Their display shows both the longevity and the continued relevance of these rights. The reverence of these documents ensures that they stand out from all others and that the social representation of the nation remains salient in the eyes and minds of visitors. It communicates the underlying ideology (macro) to the individual (micro).

Important cultural carriers are also found outside the National Archives, in broader society. Consider the case of Martin Luther King Jr., a man who spent his life creating and defining a movement of freedom and equality for all. It took eighteen years after his death to have a national holiday memorializing his actions, and the actions of so many that forever changed the country. The development of Martin Luther King Jr. as a personification of equality took years of hard work, demonstrations, and recognitions from the State to the Federal level. Dr. King is used as a social representation to remind us all that freedoms are not so easily given, but that those who are oppressed can find the strength to fight back and gain what they deserve. Again, we see the power of rights, and the duty of all citizens to ensure the equality of these rights, focused through the idolization of Dr. King. We are able to propagate the normative system of rights through these objects and individuals by distancing their reality until they are generalized beyond themselves - hyper-generalized into a notion and a feeling of pride and sacredness, that is, a social representation.

One of the most sacred locations to visit in the Washington D.C. area is the Tomb of the Unknown Soldier. There are guards at this site twenty-four hours a day, 365 days a year. While on duty, the guards are not ranked, so as to not outrank the lost soldier. A serious atmosphere is maintained and the guards are quick to scold anyone who breaks the rules. People come to watch soldiers march back and forth for hours at a time. Of course, there is more to the ceremony than pacing back and forth. Each step, each second, is meticulously planned and practiced to indicate 
the utmost respect those who fell in past wars. This social representation too evokes social memories and allows for a sense of continuity between past, present and future in service of the nation. It instills pride and esteem in citizens and clearly demonstrates the self-efficacy of the ingroup and its members.

Yet, if there is a single cultural carrier for the American political system, it lies in the heart of Washington - the White House. Not even the statue of Abraham Lincoln or the Home of George Washington is as powerful as the White House in representing and propagating American political values. Irrespective of the particular individual who serves as President at any one time, the White House carries forward values and beliefs that are part of the American heritage. The evolution of the White House as a national carrier reflects influence from macro, to meso, to micro levels: powerful political and economic (macro) forces use and propagate the White House as a national carrier reflecting power and status, schools and other meso level groups (e.g., the family, the church) assimilate and further communicate the meaning of the White House as national carrier, individuals (particularly children) are socialized to perceive and adopt this meaning for the White House. Throughout the centuries, although the White House has been re-built a number of times, the national role it plays has remained constant. However, cultural carriers become transformed as well, as we saw when the Twin Towers are destroyed in the 9/11 terrorist attacks and Freedom Tower was built to carry forward American ideals.

\section{Concluding thoughts}

We have discussed what continues to be the greatest challenge for social psychology, explaining the integration of individuals and societies. An interesting possibility is that Social Representations Theory and Identity Process Theory may provide an integrative heuristic framework for understanding the links between macro, meso and micro processes. Objects, places and spaces can become social representations of the state, its ideology, and other macrolevel phenomena, which are subsequently displayed and brandished so that they can resonate with groups and individuals within society. These social representations, or cultural carriers, are continually being transformed, as individuals and groups compete to make their own meaning systems dominant in inter-personal, inter-group and societal relationships. Just as the Islamic veil and the Confederate Flag, 'just pieces of cloth', are fought over, so too is there a fight around the globe about the meaning of the Twin Towers and Freedom Tower. At a global level, also, social 
representations are in continuous transformation and dispute. Yet, those that are central to identity will be maintained and defended with fervor.

\section{References}

Apter, M. (1983) Negativism and the sense of identity. In G.M. Breakwell (Ed.) Threatened identities (pp.75-90). Chichester: Wiley.

Bowen, J.R. (2007). Why the French don't like headscarves. Islam, the state and public space. Princeton: Princeton University Press.

Breakwell, G.M. (1986). Coping with threatened identities. London: Methuen.

Breakwell, G. M. (2001a). Social representational constraints upon identity processes. In K. Deaux and G. Philogene (eds.), Representations of the social: bridging theoretical traditions (pp. 271-84). Oxford: Blackwell.

Breakwell, G.M. (2014). Identity and social representations. In R. Jaspal and G.M. Breakwell (eds). Identity process theory: identity, social action and social change (pp.118-34). Cambridge: Cambridge University Press.

Coski, J. (2005). The Confederate battle flag: America's most embattled emblem. Cambridge, MA: Belknap Press of Harvard University Press.

Doise, W., Spini, D. \& Clémence, A. (1999). Human rights studied as social representations in a cross-national context. European Journal of Social Psychology, 29, 1-29.

Doise , W. Staerkle , C. Clemence , A. Savory , F. (1998). Human rights and Genevan youth: a developmental study of social representations. Swiss Journal of Psychology, 57, 86-100. 
Harré, R., \& Moghaddam, F. M. (2012). Psychology for the third millennium: Integrating cultural and neuroscience perspectives. London: Sage.

Jaspal, R. (2014). Social psychological debates about identity. In R. Jaspal and G.M. Breakwell (eds). Identity process theory: identity, social action and social change (pp.3-19). Cambridge: Cambridge University Press.

Jaspal, R. \& Breakwell, G.M. (eds.) (2014). Identity process theory: identity, social action and social change. Cambridge: Cambridge University Press.

Jaspal, R. \& Coyle, A. (2014). Threat, Victimhood and Peace: Debating the 2011 Palestinian UN State Membership Bid. Digest of Middle East Studies, 23(1), 190-214.

Jaspal, R., Nerlich, B . \& Cinnirella, M. (2014). Human Responses to Climate Change: Social Representation, Identity and Socio-Psychological Action. Environmental Communication: A Journal of Nature and Culture, 8(1), 110-130.

Lyons, E. (1996). Coping with social change: processes of social memory in the reconstruction of identities. In G. M. Breakwell and E. Lyons (eds.), Changing European identities: sociopsychological analyses of social change (pp. 31-40). Oxford: Butterworth-Heinemann.

Moghaddam, F. M. (2002). The individual and society: A cultural integration. New York, NY: Worth Publishers.

Moscovici, S. (1988). Notes towards a description of social representations. European Journal of Social Psychology, 18, 211-250.

Philogène, G. (1999). From Black to African American: A New Social Representation. Westport, CT: Praeger Publishers. 
Powell, J. (2007). Psychological social psychology. In G. Ritzer (Ed.), Blackwell encyclopedia of sociology. Chichester: Wiley-Blackwell.

Rohall, D.E., Milkie, M.A. \& Lucas, J.W. (2011). Social psychology: sociological perspectives. London: Pearson.

Tolstoy, L. (1869/1957). War and peace (2 vols.). Translated by R. Edmonds. Harmondsworth, Middlesex, England: Penguin.

Valsiner, J., \& Rosa, A. (Eds.) (2007). The Cambridge handbook of sociocultural psychology. New York, NY.: Cambridge University Press. 